\title{
Mitral Cells in the Olfactory Bulb Are Mainly Excited through a Multistep Signaling Path
}

\author{
David H. Gire, ${ }^{1,2 \star}$ Kevin M. Franks, ${ }^{3 \star}$ Joseph D. Zak, ${ }^{2}$ Kenji F. Tanaka, ${ }^{3}$ Jennifer D. Whitesell, ${ }^{1,2}$ Abigail A. Mulligan, ${ }^{3}$ \\ René Hen, ${ }^{3,4,5}$ and Nathan E. Schoppa ${ }^{2}$ \\ ${ }^{1}$ Neuroscience Program, ${ }^{2}$ Department of Physiology and Biophysics, University of Colorado, Denver, Anschutz Medical Campus, Aurora, Colorado 80045, \\ and Departments of ${ }^{3}$ Neuroscience, ${ }^{4}$ Pharmacology, and ${ }^{5}$ Psychiatry, Columbia University Medical Center, New York, New York 10032
}

Within the olfactory system, information flow from the periphery onto output mitral cells (MCs) of the olfactory bulb (OB) has been thought to be mediated by direct synaptic inputs from olfactory sensory neurons (OSNs). Here, we performed patch-clamp measurements in rat and mouse $\mathrm{OB}$ slices to investigate mechanisms of OSN signaling onto MCs, including the assumption of a direct path, using electrical and optogenetic stimulation methods that selectively activated OSNs. We found that MCs are in fact not typically activated by direct OSN inputs and instead require a multistep, diffuse mechanism involving another glutamatergic cell type, the tufted cells. The preference for a multistep mechanism reflects the fact that signals arising from direct OSN inputs are drastically shunted by connexin 36-mediated gap junctions on MCs, but not tufted cells. An OB circuit with tufted cells intermediate between OSNs and MCs suggests that considerable processing of olfactory information occurs before its reaching MCs.

\section{Introduction}

Mitral cells (MCs) are a major output channel of the olfactory bulb (OB), sending signals to various olfactory cortical structures (Shepherd et al., 2004). In terms of signaling from the periphery onto MCs, it is widely believed that information flow occurs at direct synaptic connections from olfactory sensory neurons (OSNs) onto MCs. However, there is only weak evidence supporting the assumption that direct OSN inputs can drive action potentials (spikes) in MCs. While recent ultrastructural studies suggest that OSN-to-MC synaptic contacts may exist (Kosaka et al., 2001; Najac et al., 2011), whether such contacts can elicit spikes may be limited by a low number of synapses or if synaptic signals are modulated by the postsynaptic dendrite (Stuart and Spruston, 1998). Reports exist of kinetically fast electrical signals at the MC soma, the likely site of spike initiation under most

Received Nov. 5, 2011; revised Dec. 16, 2011; accepted Jan. 4, 2012.

Author contributions: D.H.G., K.M.F., and N.E.S. designed research; D.H.G., K.M.F., J.D.Z., J.D.W., A.A.M., and N.E.S. performed research; K.M.F., K.F.T., and R.H. contributed unpublished reagents/analytic tools; D.H.G., K.M.F., J.D.Z., J.D.W., and N.E.S. analyzed data; D.H.G., K.M.F., and N.E.S. wrote the paper.

This work was supported by NIH Grant F31 DC009118 (D.H.G.), by The Robert Leet and Clara Guthrie Patterson Trust and NIH Grant K99 DC009839 (K.M.F.), by National Institutes of Natural Sciences Cell Sensor Project 2008 2009 and National Alliance for Research on Schizophrenia and Depression (K.F.T.), by NIH Grant 2T32 NS0077083 (J.D.W.), by New York State Stem Cell Science (R.H.), and by NIH Grant R01 DC006640 (N.E.S., J.D.Z.). We thank Drs. Diego Restrepo and Sukumar Vijayaraghavan for helpful discussions. K.M.F. is very grateful to Richard Axel and Steven Siegelbaum for their continued support and encouragement, and to Adam Hantman for valuable discussions. We thank D. Paul (Harvard University, Cambridge, MA) for the gift of Cx36 KO mice, and the NIH (Grant EY014127), which supported his work.

The authors declare no competing financial interests.

*D.H.G. and K.M.F. contributed equally to this work.

Correspondence should be addressed to Nathan E. Schoppa, Department of Physiology and Biophysics, University of Colorado, Anschutz Medical Campus, Mail Stop 8307, P.0. Box 6511, Aurora, C0 80045. E-mail: nathan.schoppa@ucdenver.edu.

K. F. Tanaka's present address: Division of Neurobiology and Bioinformatics, National Institute for Physiological Science, 0kazaki 444-8787, Japan.

DOI:10.1523/JNEUROSCI.5580-11.2012

Copyright $\odot 2012$ the authors $\quad 0270-6474 / 12 / 322964-12 \$ 15.00 / 0$ conditions, following stimulation in the olfactory nerve (ON) layer (Chen et al., 1997; Djurisic et al., 2008; De Saint Jan et al., 2009; Najac et al., 2011). However, these signals could represent fast glutamate receptor-dependent "lateral" excitation between MCs (Schoppa and Westbrook, 2002; Urban and Sakmann, 2002; Pimentel and Margrie, 2008) rather than monosynaptic OSN transmission. Stimulation in the ON layer near a glomerulus could inadvertently excite the apical dendrite(s) of one or more MCs, resulting in glutamate release from these MCs, and MCto-MC lateral excitation.

Further confounding the question of how OSNs signal to MCs is recent physiological evidence for alternate, multistep forms of signaling. One subgroup of glutamatergic tufted cells in $\mathrm{OB}$, the external tufted (ET) cells in the glomerular layer, receive strong direct OSN inputs (Hayar et al., 2004b; Murphy et al., 2004), are activated at lower intensities of ON stimulation than MCs (De Saint Jan et al., 2009), and also can transmit glutamatergic signals to MCs (Zhou and Belluscio, 2008; De Saint Jan et al., 2009), all factors that make them well suited to mediate excitation of MCs. In addition, ON stimulation elicits a "long-lasting depolarization" (LLD), which is a polysynaptic excitatory event synchronized across all MCs at a glomerulus (Carlson et al., 2000; Schoppa and Westbrook, 2001). The relative importance of direct versus multistep mechanisms for activating MCs is unresolved, and much emphasis has remained on the importance of direct OSN signals (Najac et al., 2011).

Here, we used a functional approach to assess the contribution of direct versus multistep mechanisms of signaling from OSNs onto MCs, with patch-clamp recordings in rodent $\mathrm{OB}$ slices. To ensure selective stimulation of OSNs, avoiding MC-to-MC lateral excitation, we used weaker electrical stimuli, and also recorded light-evoked signals from transgenic mice that selectively express channelrhodopsin-2 (ChR2) in OSNs. We provide evi- 
dence that most MCs in fact fail to receive significant direct OSN signals at their cell bodies and that such signaling is much more prominent on different classes of tufted cells. This difference in direct signaling reflects different levels of shunting by gap junctions. While MCs receive weak direct OSN signals, they receive strong signals through a tufted cell-mediated path.

\section{Materials and Methods}

All experiments were conducted under protocols approved by the Animal Care and Use Committees of the University of Colorado, Anschutz Medical Campus, and Columbia University Medical Center.

Electrophysiological recordings in rat $O B$ slices. Horizontal slices (300$400 \mu \mathrm{m}$ ) were prepared from OBs of Sprague Dawley rats of either sex (P10-P30) following general isoflurane anesthesia and decapitation, as described previously (Schoppa et al., 1998). Bulb slices were viewed using an upright Axioskop 2FS microscope (Carl Zeiss) with differential interference contrast optics video microscopy and a CCD camera. Cells were visualized with a $40 \times$ water-immersion objective. All experiments were done at $32-35^{\circ} \mathrm{C}$.

The base extracellular recording solution contained the following (in $\mathrm{mm}$ ): $125 \mathrm{NaCl}, 25 \mathrm{NaHCO}_{3}, 1.25 \mathrm{NaH}_{2} \mathrm{PO}_{4}, 25$ glucose, $3 \mathrm{KCl}, 2 \mathrm{CaCl}_{2}, 1$ $\mathrm{MgCl}_{2}, \mathrm{pH} 7.3$, and was oxygenated $\left(95 \% \mathrm{O}_{2}, 5 \% \mathrm{CO}_{2}\right)$. Patch pipettes for whole-cell recordings (5-7 M $\Omega$ ) contained $125 \mathrm{~K}$-gluconate, $2 \mathrm{MgCl}_{2}, 0.025$ $\mathrm{CaCl}_{2}$, 1 EGTA, $2 \mathrm{NaATP}, 0.5 \mathrm{NaGTP}, 10$ HEPES, pH 7.3 with KOH. Some recordings used to assess OSN-EPSCs in MCs $(n=3)$ were done using cesium in the pipette; results obtained were similar to K. In some whole-cell recordings in ET/MC pairs (see Figs. 7, 8), $30 \mathrm{~mm}$ glutamic acid was added to the pipette to stabilize glutamatergic transmission (Ma and Lowe, 2007). In voltage-clamp recordings of responses to OSN stimulation, a holding potential $\left(V_{\text {hold }}=-70\right.$ to $\left.-80 \mathrm{mV}\right)$ just above $E_{\mathrm{Cl}}(-89 \mathrm{mV})$ was chosen to avoid contaminating inward currents by $\mathrm{GABA}_{\mathrm{A}}$ receptor-mediated events; evoked currents were also completely blocked by 2,3-dioxo-6-nitro-1,2,3,4tetrahydrobenzo[f quinoxaline-7-sulfonamide (NBQX) $(10 \mu \mathrm{M})$ and DL-AP5 $(100 \mu \mathrm{M} ; n=4)$. Loose cell-attached (LCA) patch recordings were made with patch pipettes filled with extracellular solution.

Current and voltage signals were recorded with Axopatch 200B or Multiclamp 700A amplifiers (Molecular Devices), low-pass filtered at $1-2 \mathrm{kHz}$, and digitized at $10 \mathrm{kHz}$. ON stimulation was done by placing a broken-tip patch pipette (10 $\mu \mathrm{m}$ diameter) in the ON layer, 50-100 $\mu \mathrm{m}$ superficial to the target glomerulus of the test cell. Brief pulses $(100 \mu \mathrm{s})$ triggered by a stimulus isolation unit were applied, with an interstimulus interval of $20 \mathrm{~s}$. Data were acquired using AxographX.

Morphological analysis of the cells, including determination of target glomeruli, was done for whole-cell recordings by including Alexa 488 $(100 \mu \mathrm{M})$ in the patch pipette. Selected MCs had apical dendrites targeted to glomeruli at the slice surface, which facilitated stimulation of OSNs at target glomeruli. For LCA patch recordings of same-glomerulus MC/ET cell pairs in Figure 2, target glomeruli of MCs were first determined by dye loading MC cell bodies via single-cell electroporation (1 mM Alexa 488 in electroporating pipette) (Gire and Schoppa, 2009). ET cells were then selected based on their proximity to the target glomeruli of the MCs. For the pair-cell image shown in Figure 1 $a$, out-of-focus fluorescence was removed with a Frangi-type morphological filter.

Cell types were defined based on several criteria. ET cells had an ellipsoid-shaped cell body (diameter, $\geq 10 \mu \mathrm{m}$ ) in the glomerular layer and apical dendrites that filled target glomeruli. They also underwent spontaneous spike bursts (Hayar et al., 2004a). "Superficial" middle tufted (SMT) and "deep" middle tufted (DMT) cells had ellipsoidshaped cell bodies in the external plexiform layer (EPL) and had at least one lateral dendrite.

Immunohistochemical analysis of ChR2-mCherry expression. Fiveweek-old mice of either sex were deeply anesthetized and decapitated. The nasal epithelia and OBs were removed and placed in 1\% paraformaldehyde (PFA) for $4 \mathrm{~h}$. The bulbs were further postfixed in 4\% PFA overnight. Nasal epithelia were then embedded in OCT and sectioned to 20 $\mu \mathrm{m}$ on an upright cryostat (Leica). Bulbs were embedded in gelatin and sliced on a Vibratome (Leica) to $80 \mu \mathrm{m}$. Tissue was incubated with blocking solution [ $5 \%$ heat-inactivated horse serum, $0.1 \%$ Triton X-100 (ep- ithelium) or $0.3 \%$ Triton X-100 (bulb) in PBS] and incubated at $4^{\circ} \mathrm{C}$ for $2 \mathrm{~h}$. Chick polyclonal anti-GFP (1:1000; Abcam) and rabbit polyclonal anti-DsRed (1:100; Clontech) antibodies were diluted in blocking solution and applied overnight at $4^{\circ} \mathrm{C}$. The next day, sections were washed and secondary Alexa 488 donkey anti-chick IgG, Alexa 555 donkey antirabbit IgG antibodies, and Neurotrace 640 (all Invitrogen) were then added to a final dilution of 1:500 and incubated overnight at $4^{\circ} \mathrm{C}$. Slices were then washed and mounted with Vectashield mounting medium (Vector Laboratories). Images were acquired using a Zeiss 710 scanning confocal microscope.

Recordings of light-evoked currents in OMP-tTA/tetO-ChR2 mice. The OBs of 4- to 5-week-old mice of either sex were quickly removed in ice-cold artificial CSF (aCSF). Horizontal slices $(300 \mu \mathrm{m})$ were cut using a Vibratome in a solution containing the following (in $\mathrm{mM}$ ): $10 \mathrm{NaCl}, 2.5 \mathrm{KCl}, 0.5 \mathrm{CaCl}_{2}$, $7 \mathrm{MgSO}_{4}, 1.25 \mathrm{NaH}_{2} \mathrm{PO}_{4}, 25 \mathrm{NaHCO}_{3}, 10$ glucose, and 195 sucrose, equilibrated with $95 \% \mathrm{O}_{2}$ and $5 \% \mathrm{CO}_{2}$. Slices were incubated at $34^{\circ} \mathrm{C}$ for $30 \mathrm{~min}$ in aCSF containing the following: $125 \mathrm{~mm} \mathrm{NaCl}, 2.5 \mathrm{~mm} \mathrm{KCl}, 1.25 \mathrm{~mm}$ $\mathrm{NaH}_{2} \mathrm{PO}_{4}, 25 \mathrm{~mm} \mathrm{NaHCO}, 25 \mathrm{~mm}$ glucose, $2 \mathrm{~mm} \mathrm{CaCl}, 1 \mathrm{~mm} \mathrm{MgCl}, 2$ $\mathrm{Na}$-pyruvate. Slices were then maintained at room temperature until they were transferred to a recording chamber on an upright microscope (Olympus Optical) equipped with a $40 \times$ objective (LUMPLFLN 40XW, $0.8 \mathrm{NA}$ ). The bath solution contained the GABA receptor antagonists 6-imino3-(4-methoxyphenyl)-1(6H)-pyridazinebutanoic acid hydrobromide (SR-95531) (10 $\mu \mathrm{M})$ and (2S)-3-[[(1S)-1-(3,4-dichlorophenyl)ethyl] amino-2-hydroxypropyl](phenylmethyl)phosphinic acid hydrochloride (CGP55845) $(10 \mu \mathrm{M})$ to isolate excitatory synaptic responses. Patch electrodes (3-6 M $\Omega$ ) contained the following: $130 \mathrm{~K}$-methylsulfate, $5 \mathrm{~mm} \mathrm{NaCl}$, 10 HEPES, 12 phosphocreatine, 3 MgATP, 0.2 NaGTP, 0.1 EGTA, 0.2 Alexa 594 cadaverine, $0.15 \%$ biocytin. Series resistance, which was always $<20$ $\mathrm{M} \Omega$, was typically compensated at $80-95 \%$.

Patched neurons were visualized with $590 \mathrm{~nm}$ light from a monochrometer and a cooled CCD camera (TILL Photonics). The recording platform was moved such that the objective was centered over the glomerular tuft of the cell. Short (1-2 ms), collimated $470 \mathrm{~nm}$ light pulses from an LED (LEDC5; Thorlabs) were delivered to the tissue through the objective (150-250 mW output of LED, 15-20 mW power at sample; FWHM, $\sim 300 \mu \mathrm{m}$ at the sample). Light pulses were applied every $15 \mathrm{~s}$. Voltage- and current-clamp responses were recorded with a Multiclamp $700 \mathrm{~A}$ amplifier, filtered at $4 \mathrm{kHz}$, and digitized at $10 \mathrm{kHz}$. Data were collected and analyzed using AxographX and IGOR Pro (Wavemetrics). All experiments were done at $34^{\circ} \mathrm{C}$. No light-evoked currents were observed in recordings done in wild-type mice $(n=5$ SMT cells; $n=2$ MCs), indicating specificity to ChR2 expression.

Modeling and electrophysiological recordings done to test function of gap junctions. Simulations of the 10-MC network model to test the role of gap junctions (see Fig. 5a) were done in NEURON (Hines and Carnevale, 1997). In the simulations, an excitatory input (conductance change with decay $\tau=2 \mathrm{~ms}$; reversal potential, $0 \mathrm{mV}$ ) was placed $5 \mu \mathrm{m}$ from the distal end of the $200 \mu \mathrm{m}$ apical dendrite of the test MC; gap junctions were placed at the end of the apical dendrites of all MCs. All MCs were connected by gap junctions to all other MCs in the model with a gap junctional conductance of $1.1 \mathrm{nS}$, matching the mean value observed in experimental measurements (see Fig. $5 d$ ). Passive membrane properties were $R_{\mathrm{m}}=15,000 \Omega-\mathrm{cm}^{2} ; C_{\mathrm{m}}=1.0 \mu \mathrm{F} / \mathrm{cm}^{2} ; R_{\mathrm{i}}=80 \Omega$-cm. The steadystate voltage in the simulations was $-60 \mathrm{mV}$.

Cx36 KO mice were generated as described previously (Deans et al., 2001). Heterozygous animals (C57/B6-129SvEv mixed background) were mated to generate knock-out $\left(\mathrm{Cx} 36^{-1-}\right)$ pups. $\mathrm{Cx} 36 \mathrm{KO}$ progeny were genotyped by PCR using primers to detect wild-type (primers A and $B$ in Deans et al., 2001) or KO (NEO) alleles (5' -TCC GGC CGC TTG GGT GGA G-3' and 5' -CAG GTA GCC GGA TCA AGC GTA TGC-3'). Recordings were made from mouse pups of either sex at P14-P21. Wildtype controls included $\mathrm{Cx} 36^{+/+}$littermates as well as unrelated C57/B6129SvEv mixed background mice. Conditions for patch-clamp recordings in MCs and tufted cells were similar to those described for rat OB slices. For electrical stimulation of OSNs, somewhat higher intensities $(30-100 \mu \mathrm{A})$ were used in mice compared with most recordings in rats $(7-38 \mu \mathrm{A})$. In mice, electrical stimulation at intensities $<30 \mu \mathrm{A}$ generally did not elicit observable synaptic responses. 
Data analysis. In the kinetic analysis of EPSCs evoked by OSN stimulation (both electrical and light), onset latencies were measured, except where noted, by visual inspection, from the time point at which the current first deviated from baseline. Because the average current traces analyzed had high signal-to-noise, this method was deemed reliable. For rise times, we generally measured the time it took for the current to pass from 10 to $90 \%$ of its peak value. In the infrequent cases in which the MC EPSC included a small fast component in addition to an LLD, reported rise times reflect only the small early component.

In the analysis of photocurrents measured in tetrodotoxin (TTx) and 4-aminopyridine (4-AP) in Figure 4, monosynaptic signals were assessed from the peak current recorded during the first $20 \mathrm{~ms}$ after light stimulation, when monosynaptic signals should have dominated the response. Similar results were obtained if peak currents were measured during a $100 \mathrm{~ms}$ window. In SMT cells, control photocurrents measured in the absence of TTx/4-AP were typically complex and biphasic, possibly reflecting the contribution of monosynaptic and polysynaptic signaling mechanisms. We did not analyze effects of TTx/4-AP on the different response components, as we expected that TTx/4-AP would attenuate and prolong the kinetics of monosynaptic signaling, making it difficult to interpret drug effects on the kinetic components; also SMT cell currents in TTx/4-AP typically were not clearly biphasic.

In the analysis of MC currents locked to ET cell spikes (see Fig. $7 c, d$ ), an event detection routine was first used to find spikes in ET cells; spikelocked averages were then constructed from currents aligned to all detected spikes. In the analysis, we selected response trials in which the ET cell displayed single spikes isolated from all other spikes by $50 \mathrm{~ms}$; these differed from the most common response type in which ET cells had rapidly occurring spike bursts after ON stimulation (see Fig. 2). This selection procedure was done to facilitate the kinetic comparison between the ET spike and MC current, from which information about current onset delay and rise time was obtained. Although we could not exclude the possibility that the ET spikes observed in these trials were spontaneously occurring, they were likely evoked by ON stimulation. Spontaneously occurring spikes were rarely observed during a $1 \mathrm{~s}$ period that preceded ON stimulation.

Statistical significance was determined via Student's $t$ test. Data values are reported as means \pm SE. The asterisks in the figures indicate statistical significance at $p<0.05$.

\section{Results \\ Negligible direct OSN signals on MCs following electrical stimulation}

For assessing direct OSN signaling onto MCs, we first obtained somatic recordings of EPSCs from voltage-clamped cells ( $V_{\text {hold }}=$ -70 to $-80 \mathrm{mV}$ ) in response to electrical stimulation of $\mathrm{ON}$ fibers in rat $\mathrm{OB}$ slices (Fig. 1). To avoid inadvertently exciting MC apical dendrites directly with the stimulating electrode, we used weaker stimuli (7-38 $\mu \mathrm{A})$, often of identifiable OSN fiber bundles terminating in the target glomerulus of a MC (10 of $16 \mathrm{MC}$ recordings); also, stimulating electrodes were placed $\geq 50 \mu \mathrm{m}$ from the target glomerulus of a MC. Stimulus intensities for all experiments were chosen to be perithreshold ( $\sim 50 \%$ success rate) for generating the all-or-none LLD. We identified a putative EPSC arising from direct OSN inputs (an "OSN-EPSC"), based on a short current onset latency following stimulation $(<4 \mathrm{~ms}$ delay) and a fast rising phase (10-90\% rise time, $<4 \mathrm{~ms})$, while an estimate of its magnitude was obtained from the peak current $\left(\mathrm{Amp}_{4 \mathrm{~ms}}\right)$ during the first $4 \mathrm{~ms}$ after OSN stimulation. Based on these criteria, the validity of which would be verified by further experiments below (see Discussion), 13 of 16 MCs displayed no putative OSN-EPSC distinct from the polysynaptic LLD (Fig. $1 a, c-e$; average onset delay across all $16 \mathrm{MCs}, 10.8 \pm 2.2 \mathrm{~ms}$; $10-90 \%$ rise time, $60 \pm 14 \mathrm{~ms} ; \mathrm{Amp}_{4 \mathrm{~ms}}=-7 \pm 3 \mathrm{pA} ; n=16$ ), while the other $3 \mathrm{MCs}$ had small fast EPSCs (peak amplitude, -5 to $-40 \mathrm{pA}$ ). These electrical stimuli also failed to elicit observable fast OSN-EPSPs during current-clamp recordings ( $n=6 \mathrm{MCs}$ ). Stronger electrical stimuli $(\geq 100 \mu \mathrm{A})$ often evoked large $(>200$ pA) rapid-onset EPSCs in MCs (onset delay, $2.4 \pm 0.1 \mathrm{~ms} ; n=$ 16), but these likely had contributions from MC-to-MC lateral excitation. During current-clamp recordings in MCs, ON stimulation at these higher intensities typically resulted in directly evoked spikes occurring in $<1 \mathrm{~ms}(n=22)$.

A possible explanation for the negligible OSN-EPSCs and EPSPs in MCs is that it reflected poor stimulation of OSNs, especially given that weaker electrical stimuli were required to avoid MC-to-MC lateral excitation. However, in recordings in ET cells, which receive direct inputs (Hayar et al., 2004b; Murphy et al., 2004), we found large fast OSN-EPSCs in every cell examined (onset delay, $1.6 \pm 0.1 \mathrm{~ms} ; 10-90 \%$ rise time, $1.7 \pm 0.2 \mathrm{~ms}$; $\mathrm{Amp}_{4 \mathrm{~ms}}=-238 \pm 73 \mathrm{pA} ; n=13$; Fig. $\left.1 a, c-e\right)$. These included four ET cell recordings done during simultaneous dual-cell recordings with MCs that sent apical dendrites to the same glomerulus and that lacked fast EPSCs (see "same-glomerulus" example in Fig. 1a). Large OSN-EPSCs were also observed in all SMT cells located in the superficial part of the EPL (within $50 \mu \mathrm{m}$ of glomerular layer; $\mathrm{Amp}_{4 \mathrm{~ms}}=-150 \pm 51 \mathrm{pA} ; n=9$; Fig. $1 b-e$ ), and in some (3 of 8) DMT cells with cell bodies in more inner regions of the EPL $\left(\mathrm{Amp}_{4 \mathrm{~ms}}=-65 \pm 35 \mathrm{pA} ; n=8\right.$; Fig. $\left.1 c-e\right)$. Thus, OSN stimulation appeared to be robust (see Discussion for further discussion).

The negligible OSN-EPSCs in MCs were also not due to passive filtering by the comparatively long trunks of their apical dendrites (150-250 $\mu \mathrm{m}$ trunk compared with $\leq 50 \mu \mathrm{m}$ for ET and SMT cells). Recording from the MC apical dendrite at distances $\leq 50 \mu \mathrm{m}$ from the tuft failed to reveal substantial fast OSN signals $\left(\mathrm{Amp}_{4 \mathrm{~ms}}=-10 \pm 5 \mathrm{pA} ; n=4\right.$; Fig. $\left.1 \mathrm{f}\right)$; moreover, MCs and tufted cells had similar-sized LLDs (Fig. $1 g$ ), which, like the OSN-EPSC, originate in the apical tuft (Carlson et al., 2000). The specific recording conditions in our slice experiments also appeared not to be important. The combined addition of the $\mathrm{GABA}_{\mathrm{B}}(\mathrm{CGP} 55845 ; 10 \mu \mathrm{M})$ and dopamine (sulpiride; $100 \mu \mathrm{M}$ ) receptor antagonists, which should eliminate possible downregulatory effects on release due to residual GABA or dopamine in the slice (Nickell et al., 1994; Aroniadou-Anderjaska et al., 2000; Ennis et al., 2001; McGann et al., 2005), did not increase fast currents in MCs (35 $\pm 14 \%$ reduction in $\mathrm{Amp}_{4}$ ms values; $\left.n=4\right)$. Furthermore, raising extracellular calcium from our normal 2 $\mathrm{mm}$ concentration to $6 \mathrm{~mm}$, which could enhance transmitter release, did not increase fast currents $(28 \pm 16 \%$ reduction in $\mathrm{Amp}_{4 \mathrm{~ms}}$ values; $\left.n=4\right)$. One factor that appeared to have a modest impact on the putative direct OSN signal was the age of the animal, as fast signals in MCs were larger in older rats at P24-P30 $\left(\mathrm{Amp}_{4 \mathrm{~s}}=-20 \pm 5 \mathrm{pA} ; n=5 ; p=0.013\right)$ compared with $\mathrm{P} 10-\mathrm{P} 14\left(\mathrm{Amp}_{4 \mathrm{~ms}}=-1.8 \pm 0.8 \mathrm{pA} ; n=11\right)$. However, the early signals even in older animals were 10 -fold smaller than in tufted cells (approximately $-250 \mathrm{pA}$ in ET cells).

A final issue addressed in this initial analysis of direct OSN signaling was the possibility that our whole-cell patch recordings of somatic EPSCs and EPSPs may not have provided an accurate measure of the ability of OSNs to drive spikes in MCs. OSNs may under some conditions elicit spikes initiated in the MC apical dendrites (Chen et al., 1997). However, we found that MC spike activity (Fig. $2 a-c$ ), recorded during simultaneous LCA patch recordings from same-glomerulus MCs and ET cells (see Materials and Methods), closely matched the somatic EPSCs (Fig. 1a). With weaker ON stimuli $(10-40 \mu \mathrm{A})$ similar to those used in recordings of EPSCs, MC spikes always occurred as a delayed and long-lasting barrage of activity (time-to-first spike, $185 \pm 55$ ms; 
a

(i)

\section{ET cell-MC pair}

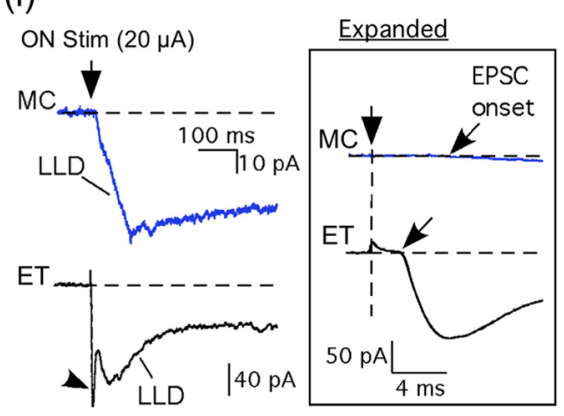

b

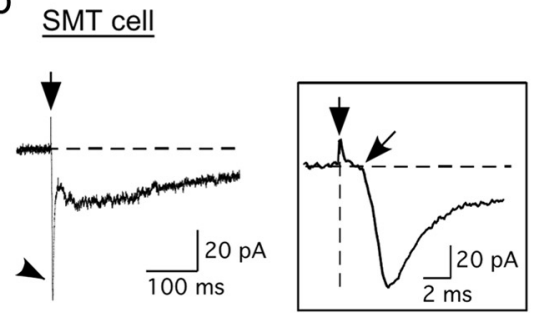

(ii)
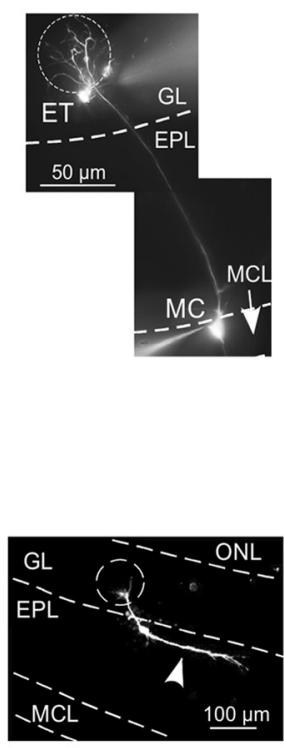

f
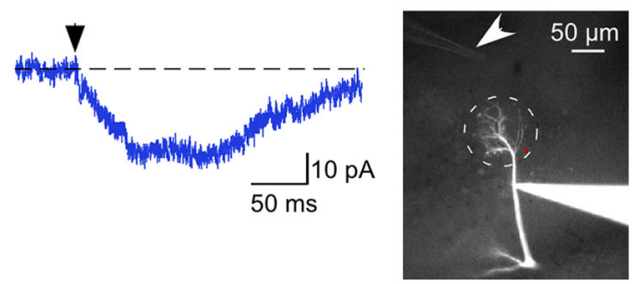

C
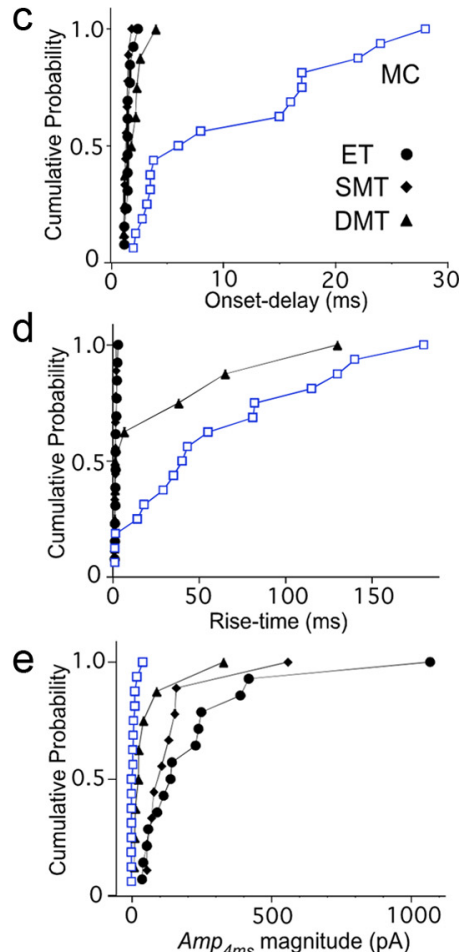

9

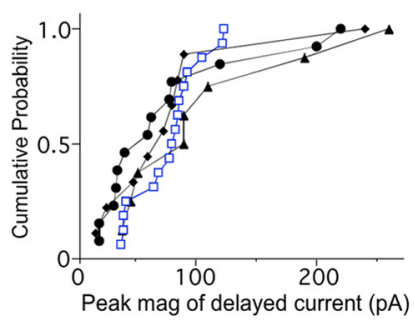

Figure 1. Assessment of direct OSN-EPSCs following electrical stimulation. ai, EPSCs recorded simultaneously from a same-glomerulus MC/ET cell pair in response to $0 \mathrm{~N}$ stimulation (20 $\mu \mathrm{A})$. The ET cell, but not the MC, displayed a fast-occurring EPSC (arrowhead) distinct from a longer-lasting LLD. The diagonal arrows on expanded traces indicate estimated onset times for the EPSCs. All traces in figure are averages of $4-15$ responses. aii, Images of the MC/ET cell pair from ai filled with Alexa 488 (100 $\mu \mathrm{m})$. Labeled is the target glomerulus of the two cells (dashed ring), as well as glomerular $(\mathrm{GL})$, external plexiform (EPL), and mitral cell (MCL) layers. $\boldsymbol{b}$, EPSC evoked in an SMT cell by ON stimulation (13 $\mu \mathrm{A})$. Like the ET cell in $\boldsymbol{a}$, the SMT cell had a distinct rapid EPSC, in addition to a slow LLD. This cell had one prominent lateral dendrite (arrowhead on cell image). c, Summary of EPSC onset delays across all MCs $(n=16)$, ET cells $(n=13)$, SMT cells $(n=9)$, and DMT cells $(n=8)$, plotted as a cumulative histogram. Each data point reflects one cell. $\boldsymbol{d}$, EPSC rise times (10-90\%) across all recordings. $\boldsymbol{e}$, Amplitudes of putative OSN-EPSCs across all recordings, estimated from the peak $\left(\mathrm{Amp}_{4 \mathrm{~ms}}\right.$ ) measured during the first $4 \mathrm{~ms}$ after $\mathrm{ON}$ stimulation. $f$, A dendritic recording of the $\mathrm{MC}$ response to $0 \mathrm{~N}$ stimulation (100 $\mu \mathrm{s}, 27 \mu \mathrm{A}$; at white arrowhead on cell image) did not reveal a substantial fast OSN-EPSC. $\boldsymbol{g}$, All cell types showed similar-sized LLDs (measured $\geq 30 \mathrm{~ms}$ after $0 \mathrm{~N}$ stimulation), also consistent with at most modest passive filtering effects by the trunk of the apical dendrites.

$n=5)$, reflecting its close association with the polysynaptic LLD (Gire and Schoppa, 2009). In contrast, ET cells had a distinct fast component of spikes (time-to-first spike, $11 \pm 2 \mathrm{~ms} ; n=5 ; p=$ 0.029 in comparisons with MCs), presumably driven by direct OSN inputs, as well as a population of delayed spikes. Stimulation at somewhat higher intensities (up to $70 \mu \mathrm{A}$ ) also resulted in delayed MC spikes (time-to-first spike, $68 \pm 19 \mathrm{~ms} ; n=8$ ). OSN stimulus patterns (four pulses separated by $10 \mathrm{~ms}$ ) also failed to elicit fast-onset spikes ( $\leq 20 \mathrm{~ms}$ delay) in MCs $(n=6)$, providing evidence that MC spiking does not result directly from summating OSN inputs.

\section{Photoactivation-induced OSN signaling}

We next turned to an optogenetic strategy for stimulating OSNs, using mice that selectively expressed ChR2 in OSNs (Dhawale et al., 2010). This method allowed us to stimulate OSNs broadly without concern about directly activating MCs and hence MCto-MC lateral excitation. Specific expression of ChR2 in OSNs was obtained by generating a transgenic mouse line with a bidi- rectional tetO (Bi-tet) promoter linked to the cDNA of a ChR2mCherry construct and an NpHR-EGFP construct in the reverse orientation (Fig. 3a) (Chuhma et al., 2011). These mice were crossed to a mouse strain that encodes the tTA gene under the control of the OMP promoter (OMP-IRES-tTA) (Yu et al., 2004). OMP is specifically expressed in OSNs such that cells that activate OMP gene transcription will express a bicistronic RNA encoding both OMP and tTA. The expression of tTA should then direct the synthesis of both ChR2-mCherry and NpHR-EGFP protein in all such OSNs. As expected, mice positive for both OMP-IRES-tTA and the tetO transgene expressed $\mathrm{ChR} 2$-mCherry throughout the nasal epithelium (Fig. 3b). ChR2-mCherry expression was seen across the apical-basal axis of OSNs in the epithelia and, importantly for our experiments, in axons of OSNs in the outer nerve layer and glomeruli of $\mathrm{OB}$.

We obtained voltage-clamp recordings from both MCs and tufted cells $\left(V_{\text {hold }}=-70 \mathrm{mV}\right.$ ) in acute brain slices from double-positive (OMP-IRES-tTA and ChR2-mCherry), ChR2expressing mice (Fig. 3c). The SMT subgroup of tufted cells was 
chosen for comparisons with MCs, since SMT cells were more easily discriminated in mice than ET cells. Brief flashes (1-2 ms, 150-250 mW output of LED, 15-20 mW power at sample) of $470 \mathrm{~nm}$ light focused on the target glomeruli of test cells produced inward excitatory currents that were completely blocked by the glutamate receptor antagonists 6-cyano-7-nitroquinoxaline2,3-dione (CNQX) $(10 \mu \mathrm{M})$ and D-(-)-2amino-5-phosphonopentanoic acid (D-AP5) (50 $\mu \mathrm{M} ; n=3$ SMT cells and 3 MCs). In terms of photocurrent kinetics, most MCs failed to display a putative OSN-EPSC occurring in $<4$ ms (in 8 of 11 cells; mean onset delay measured from start of light flash, $4.7 \pm 0.4 \mathrm{~ms} ; 10-90 \%$ rise time, $10.8 \pm 5.2 \mathrm{~ms} ; \mathrm{Amp}_{4 \mathrm{~ms}}=-22 \pm 18 \mathrm{pA}$; $n=11$ ), which was in contrast to SMT cells, which always showed fast currents (onset delay, $2.4 \pm 0.1 \mathrm{~ms} ; 10-90 \%$ rise time, $2.3 \pm 0.3 \mathrm{~ms} ; \mathrm{Amp}_{4 \mathrm{~ms}}=-634 \pm$ $201 \mathrm{pA} ; n=13 ; p<0.01$ in comparisons of onset delays and $\mathrm{Amp}_{4}$ ms values with MCs; Fig. $3 d-f)$. The presence of large $\sim 600$ pA currents in SMT cells occurring in 2-3 ms was important since it confirmed that light-evoked OSN stimulation was very robust and, also, rapid. Thus, the kinetics of the photocurrents confirmed that OSN signals are negligible at the cell bodies of most MCs. There were some differences between the kinetics of the photocurrents compared with currents evoked by electrical stimulation (Fig. 1). For example, the mean onset time of the MC current evoked by light ( $\sim 5 \mathrm{~ms}$ ) was faster than for electrical stimulation $(\sim 11 \mathrm{~ms})$. This difference likely reflected the stronger stimulus to OSNs provided by light, which resulted in faster multistep OSN-to-tufted cell-to-MC signaling (see below). What was most important was that the onset time for the MC photocurrent, while faster than for the MC current evoked by electrical stimulation, was still generally slower than what would be expected for monosynaptic signaling.

The expression of ChR2 in OSN neurons provided an additional independent way to determine how much of the MC EPSC reflects a direct OSN-EPSC. The currents in Figure $3 c$ were likely initiated by light driving fast sodium spikes in OSNs, but lightactivated synaptic responses can also be evoked in the presence of the sodium channel blocker TTx and the potassium channel blocker 4-AP (Petreanu et al., 2009). In this case, light activates ChR2 in the presynaptic terminal, which depolarizes and activates voltage-gated calcium channels coupled to the neurotransmitter release machinery. Recordings in TTx/4-AP should differentiate monosynaptic versus polysynaptic mechanisms, since the latter, requiring activation of at least one intermediate cell, should be much more sensitive to TTx/4-AP. As expected if polysynaptic mechanisms are dominant in MCs, we found that TTx $(1 \mu \mathrm{M})$ and 4-AP $(100 \mu \mathrm{M})$ nearly abolished the MC photocurrent (Fig. $4 a, b)$, as measured by peak current amplitude $(5 \pm$ $2 \%$ of current remaining; $n=10$ ) or charge integral ( $7 \pm 3 \%$ of charge remaining; $n=10$ ). The residual MC current in TTx (Fig. $4 c$ ) was very small $(<20 \mathrm{pA}$ magnitude) in 7 of $10 \mathrm{MCs}$, and averaged $-25 \pm 11 \mathrm{pA}(n=10)$. In contrast, a 10 -fold larger current remained in TTx in SMT cells (residual current, $-244 \pm$ $67 \mathrm{pA} ; n=13 ; p=0.0066$ in comparisons with MCs; Fig. $4 a-c$ ). Sufficient quantities of TTx were added, since trains of spikes evoked by direct depolarization of MCs and SMT cells (400 pA current pulses; $1 \mathrm{~s}$ ) were completely blocked ( 10 of $10 \mathrm{MCs}$ and 13 of 13 SMT cells). In some experiments (6 MCs and 9 SMT cells), D-AP5 $(50 \mu \mathrm{M})$ was added to the TTx/4-AP-containing test solution to account for possible TTx-insensitive, NMDA receptor-dependent dendrodendritic excitation (Isaacson and Strowbridge, 1998). The inclusion of AP5 had no significant effect on residual current amplitude $(p=0.17$ for MCs; $p=0.37$ for SMT cells).

The different effects of TTx/4-AP on mitral and tufted cell responses corroborates the main conclusion of the kinetic analysis, which is that most MCs have a very small direct OSN-EPSC at their cell bodies, whereas tufted cells are strongly excited by direct OSN inputs. It should be pointed out that our combined results do leave open the possibility that a fraction of MCs have modest monosynaptic OSN signals. The kinetic analysis above showed that some MCs had small-to-moderate putative OSN-EPSCs in response to electrical stimuli ( 3 of $16 \mathrm{MCs}$ ) or light (3 of $11 \mathrm{MCs}$ ), a result that was also seen in our TTx experiments.

\section{Shunting of OSN signals by $\mathrm{Cx} 36$-mediated gap junctions} What explains the very small direct OSN signal in MCs? Because recent evidence suggests that MCs may receive anatomical con- 
a

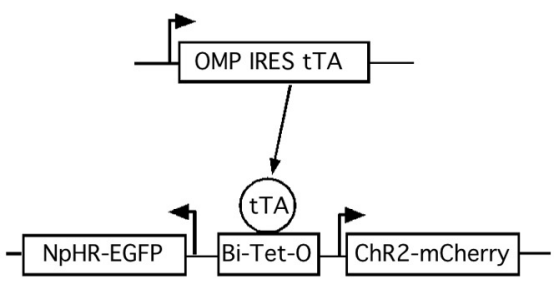

b

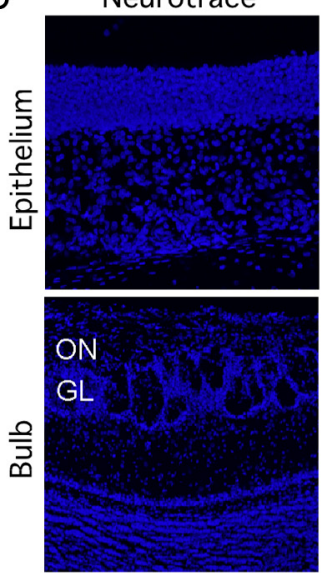

mCherry
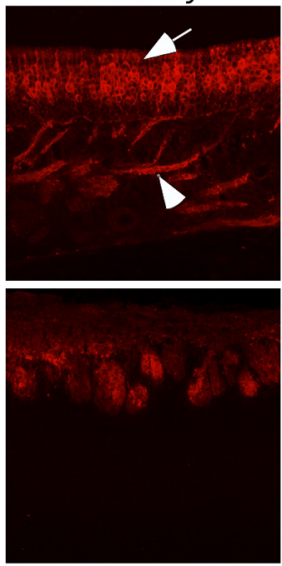

merged

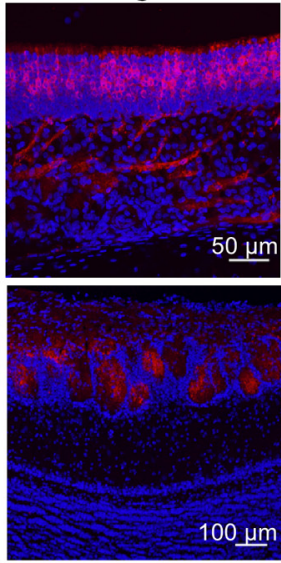

C

Mitral cell
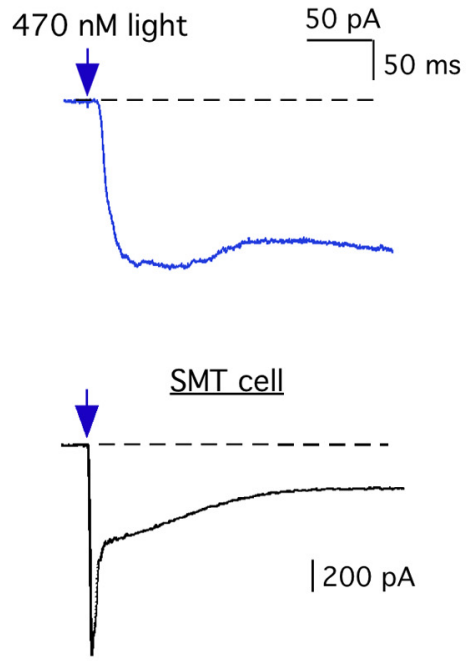

Expanded
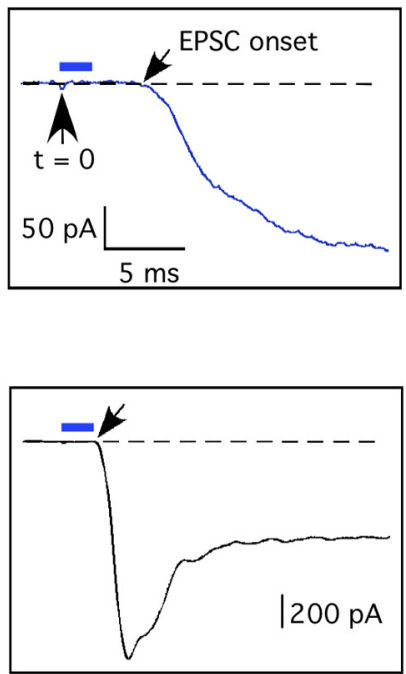

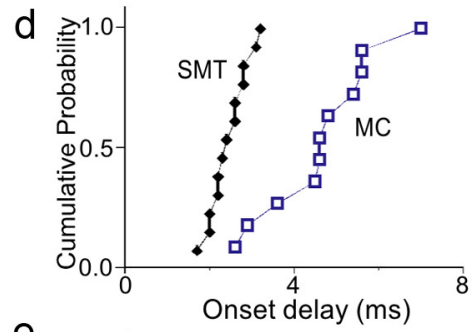

e

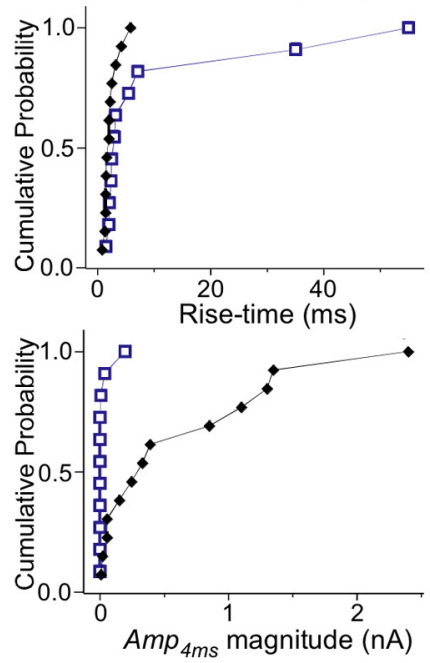

Figure 3. Kinetic analysis of OSN signaling driven by photoactivation of channelrhodopsin-2. $\boldsymbol{a}$, Schematic representation of the strategy used to express ChR2-mCherry in 0SNs. The transgene, tet0-ChR2-mCherry, can be activated in sensory neurons by expression of tTA from the OMP-IRES-tTA locus. $\boldsymbol{b}$, Expression of ChR2-mCherry in the olfactory epithelium (top panels) and ON and glomerular layers of the $\mathrm{OB}$ (bottom panels). In the epithelium, ChR2 can be seen expressed in the dendritic cilia of OSNs (white arrow in mCherry panel) as well as in their basal axon bundles (arrowhead). Glomeruli in OB are demarcated by surrounding Neurotrace-stained cell bodies. c, Photocurrents in a MC (top) and SMT cell (bottom) evoked by a $2 \mathrm{~ms}$ pulse of $470 \mathrm{~nm}$ light. In the SMT cell, but not the MC, there was a distinct fast current occurring with a short onset. All traces in Figures 3 and 4 are averages of $6-10$ responses. $\boldsymbol{d}-\boldsymbol{f}$, Summary of EPSC measurements across 11 MCs and 13 SMT cells. Plotted are onset delays, $10-90 \%$ rise times, and measurements of $\mathrm{Amp}_{4 \mathrm{~ms}}$. The onset delays in $\boldsymbol{d}$ and $\mathrm{Amp}_{4 \mathrm{~ms}}$ values in $\boldsymbol{f}$ were timed with respect to the start of the $2 \mathrm{~ms}$ light pulse. Significant differences $(p<0.01)$ were observed between MCs and SMT cells for onset delays and Amp ${ }_{4 \mathrm{~ms}}$ values, but not for rise times $(p=0.13)$.

tacts from OSNs (Kosaka et al., 2001; Najac et al., 2011), we considered the possibility that the small signals recorded in the soma reflect shunting by specific conductances in the postsynaptic dendritic membrane. For MCs, Cx36-mediated gap junctions appear to be an excellent candidate for a conductance capable of attenuating direct OSN signals. These gap junctions occur at a high level on MC apical dendrites (Kosaka and Kosaka, 2004; Christie et al., 2005), contributing to significant electrical coupling between every MC affiliated with one glomerulus (Schoppa and Westbrook, 2002; Pimentel and Margrie, 2008). Furthermore, if one computes excitatory synaptic responses in a neural network model that includes the experimentally observed all-to- all coupling between MCs at a glomerulus (Fig. $5 a$ ), there is dramatic attenuation of the MC response because of the shunting effects of gap junctions.

An additional requirement of a mechanism in which shunting by gap junctions causes weak direct OSN signals in MCs is that tufted cells, which have large OSN-EPSCs, are weakly coupled electrically. This is indeed what we found. During ET cell/ET cell pair recordings, a hyperpolarizing current injection into one cell $(-170 \mathrm{pA}$ average amplitude; $200-400 \mathrm{~ms}$ duration) resulted in very small signals in the other cell (Fig. $5 b, c)$, corresponding to a coupling coefficient of $0.5 \pm 0.2 \%(n=4)$. Similar weak coupling was observed in ET cell/MC pair recordings (average coupling 
coefficient, $0.7 \pm 0.1 \% ; n=6$ ). These coupling coefficients for ET cells were sixfold to eightfold smaller than values reported for MC/MC pairs $[4.0 \pm 0.7 \%$; taken from the study by Schoppa and Westbrook (2002); $p \leq 3 \times 10^{-5}$ ]. Differences were even more striking for the estimated gap junctional conductance (Parker et al., 2009) (Fig. 5d), based on pair-cell recordings involving ET cells $(0.03 \pm 0.01 \mathrm{nS}, n=4$, for ET cell/ET cell pairs; $0.05 \pm 0.01 \mathrm{nS}, n=6$, for $\mathrm{ET}$ cell/MC pairs) versus MC/MC pairs $\left(1.1 \pm 0.1 \mathrm{nS} ; n=12 ; p \leq 4 \times 10^{-6}\right)$. These conductance estimates account for differences in input resistances for ET cells versus MCs [input resistance values for MC-MC pair recordings were taken from measurements made for but not reported in the study by Schoppa and Westbrook (2002)].

To test the role of gap junctions in shunting OSN signals in MCs more directly, recordings were made in $\mathrm{Cx} 36 \mathrm{KO}$ mice, which lack gap junctional coupling between MCs (Christie et al., 2005). In these mice, we found that OSN stimulation $(30-100 \mu \mathrm{A})$ evoked large, rapid signals in every MC tested (10 of 10 cells; mean onset delay, $1.6 \pm 0.1 \mathrm{~ms} ; 10-90 \%$ rise time, $1.3 \pm 0.1 \mathrm{~ms} ; \mathrm{Amp}_{4 \mathrm{~ms}}=$ $-230 \pm 41$ pA; $n=10$; Fig. $6 a, c--e)$. These OSN-EPSCs were much larger than those evoked by OSN stimulation $(40-100 \mu \mathrm{A})$ in wild-type (WT) mice (mean onset delay, $3.7 \pm 0.4 \mathrm{~ms} ; 10-90 \%$ rise time, $9.8 \pm 2.3 \mathrm{~ms} ; \mathrm{Amp}_{4 \mathrm{~ms}}=-14 \pm$ $5 \mathrm{pA} ; n=11 ; p<0.005$ in comparisons of all parameters), and, remarkably, quite similar to the EPSCs observed in tufted cells (in WT mice; onset delay, $1.7 \pm 0.1 \mathrm{~ms} ; 10-90 \%$ rise time, $0.83 \pm$ $0.05 \mathrm{~ms} ; \mathrm{Amp}_{4 \mathrm{~ms}}=-239 \pm 45 \mathrm{pA} ; n=7$, including 3 ET cells and 4 SMT cells; Fig. $6 b-e$ ), differing only modestly in rise times $(p=0.018)$. Cx36 KO also caused concomitant changes in MC spiking during LCA recordings (Fig. $6 f$ ), greatly decreasing the time to first spike (from $40 \pm 11 \mathrm{~ms}, n=8$, in WT mice to $4.4 \pm$ $0.3 \mathrm{~ms}, n=8$, in Cx36 KO; $p=0.015)$ and introducing a distinct fast component of spiking presumably driven by direct OSN inputs.

The emergence of large OSN-EPSCs in MCs in the Cx36 KO mice appeared to occur without dramatic changes in OSN connectivity, as assessed from the size of the fast OSN-EPSC in tufted cells in $\mathrm{Cx} 36 \mathrm{KO}$ mice $\left(\mathrm{Amp}_{4 \mathrm{~ms}}=-333 \pm 50 \mathrm{pA} ; n=6\right)$ versus WT mice (approximately $-240 \mathrm{pA} ; p=0.15$; Fig. $6 g$ ). Cx36 KO also did not dramatically alter the morphology of MCs (Fig. 6a) nor cell capacitance $(20 \pm 1 \mathrm{pF}, n=7$, in WT; $23 \pm 1 \mathrm{pF}, n=6$, in $\mathrm{Cx} 36 \mathrm{KO}$ animals; $p=0.08)$. Cx36 KO did increase the MC input resistance modestly (from $57 \pm 7 \mathrm{M} \Omega, n=7$, to $83 \pm 9$ $\mathrm{M} \Omega, n=6 ; p=0.042$ ), which could have at least partially reflected loss of gap junctions.

The similar OSN-EPSCs in MCs and tufted cells in Cx36 KO mice are consistent with a model in which OSNs form many connections onto both MCs and tufted cells, but the direct OSN signal onto MCs is much more shunted by gap junctions. Importantly, the emergence of strong OSN-EPSCs in MCs in Cx36 $\mathrm{KO}$ animals also addressed several possible confounds in inter- preting the analysis of MC OSN-EPSCs at the start of this study (see above text). The KO data provided very good evidence that the absent OSN-EPSC in MCs from normal animals was not an artifact of the kinetic criteria used to evaluate direct signaling, passive filtering by the long apical dendrite of MCs, nor weak stimulation of OSNs that targeted MCs. All of these possible confounds would have been present in recordings from MCs in Cx36 $\mathrm{KO}$ animals.

MCs receive strong multistep signals mediated by tufted cells In the final section of our study, we sought to identify the main path accounting for excitation of MCs by OSNs, in the absence of a strong direct OSN-signaling mechanism. One likely alternative is a multistep path in which tufted cells act as an intermediary between OSNs and MCs. ET cells in particular receive strong direct OSN signals (Hayar et al., 2004b; Murphy et al., 2004) and, within the mouse $\mathrm{OB}$, direct stimulation of ET cells can result in glutamatergic excitation of same-glomerulus MCs (De Saint Jan et al., 2009). Thus, there is evidence for each step of an OSN-toET-to-MC signaling path.

In our studies in rat $\mathrm{OB}$, we found first, as seen in mice, that direct stimulation of single ET cells (25-100 ms depolarizing current to 400-600 pA) in ET/MC pair-cell recordings could elicit unidirectional excitatory signals in MCs (Fig. 7a,b) sensitive to the glutamate receptor blockers NBQX $(10 \mu \mathrm{M})$ and DL-AP5 (100 $\mu \mathrm{M} ;>95 \%$ block in two pair-cell recordings). The MC responses were of two distinct types, either small EPSCs (mean, $-8.3 \pm 1.5$ $\mathrm{pA} ; n=5)$ or much larger ones $(-117 \pm 18 \mathrm{pA} ; n=5)$ that reflected the polysynaptic LLD (in $\geq 20 \%$ of trials in five of five pairs). Because the LLD event occurs simultaneously in all MCs and tufted cells at a glomerulus (Gire and Schoppa, 2009), the fact 
a
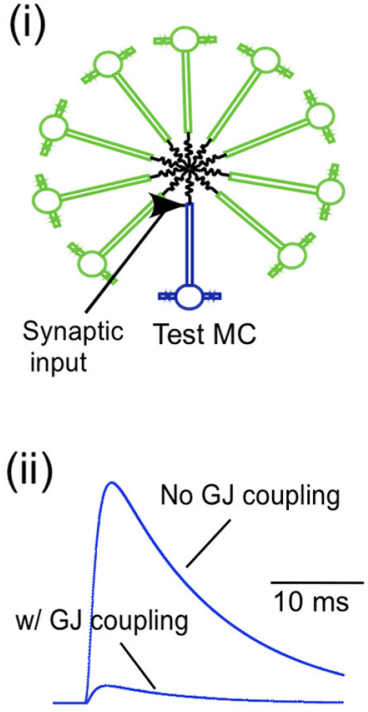

C

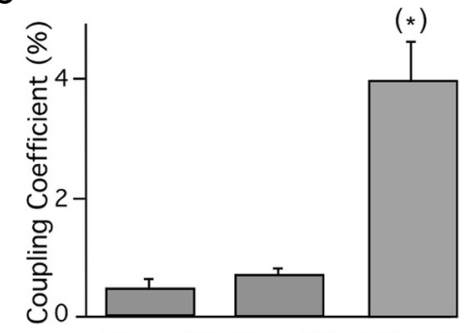

ET-to-ET ET-to-MC MC-to-MC b

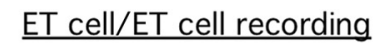

ET cell A
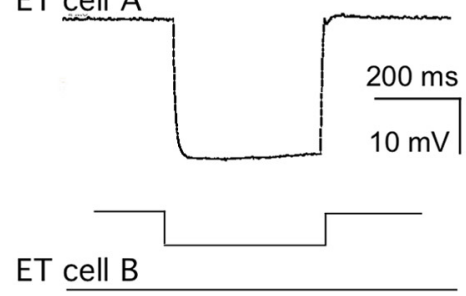

\section{Expanded ET cell B trace}

d

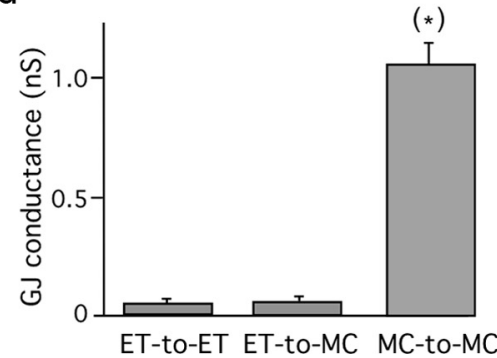

Figure 5. Mitral cells and tufted cells exhibit strong differences in electrical coupling. $\boldsymbol{a}$, Electrical coupling at MC apical dendrites reduces EPSPs in a 10-MC network model. In the simulations, an excitatory input (decay $\tau=2 \mathrm{~ms}$ ) was placed $5 \mu \mathrm{m}$ from the end of the $200 \mu \mathrm{m}$ apical dendrite of the test MC; gap junctions were placed at the end of the apical dendrites of all MCs. Every $M C$ in the model was connected to every other $M C$ with a gap junction conductance of $1.1 \mathrm{nS}$, the mean value observed experimentally (see Materials and Methods for additional details). $\boldsymbol{b}$, Electrical coupling measured in an ET cell/ET cell pair in response to hyperpolarization of one ET cell ( $400 \mathrm{~ms}$ pulse of $-200 \mathrm{pA}$ to ET cell A). The coupling coefficient for this experiment, determined from the ratio of the hyperpolarizations in the two cells ( $E T$ cell B vs ET cell A), was $\sim 0.1 \%$. c, The average coupling coefficients in ET cell/ET cell pair recordings and ET cell/MC pair recordings were much smaller than the $\sim 4 \%$ value measured in MC/MC pair recordings [from the study by Schoppa and Westbrook (2002)]. $\boldsymbol{d}$, The differences in electrical coupling among ET cells and MCs corresponded to dramatic differences in gap junctional conductance estimates. Error bars indicate SE. ${ }^{*} p<0.05$.

that only one ET cell can drive an LLD emphasizes that tufted cell-mediated multistep excitation is exceptionally strong. Direct stimulation of MCs (25-100 ms depolarizing current to 400$1000 \mathrm{pA}$, resulting in $\geq 3$ spikes), in contrast, never resulted in an LLD ( $n=5$ ET/MC pairs). ET-to-MC signaling also occurred following OSN stimulation (Fig. $7 c, d$ ). This was apparent in $\mathrm{MC} / \mathrm{ET}$ cell pair recordings as EPSCs in MCs closely locked to single isolated spikes (separated by $\geq 50 \mathrm{~ms}$ ) (see Materials and Methods) in the ET cell (delay between ET cell spike and MC current, $2.0 \pm 0.3 \mathrm{~ms} ; 10-90 \%$ rise time, $3.2 \pm 0.1 \mathrm{~ms}$; peak amplitude, $-5.3 \pm 1.5 \mathrm{pA} ; n=4$ pairs) or large-amplitude LLDs locked to ET cell spike bursts $(n=5)$. Furthermore, in simultaneous measurements of spiking in ET cells and MCs in response to OSN stimulation, ET cells displayed a distinct population of spikes that closely matched the MC spikes (see distribution of spike times in Fig. $2 b ; n=5$ ), as required if ET cells were exciting MCs.

How do tufted cells signal to MCs? Because there is no evidence for direct glutamatergic synapses between tufted cells and MCs, ET-to-MC signaling likely reflects an indirect signaling event in which glutamate diffuses a significant distance before activating MC glutamate receptors (Fig. 8a). To test this hypoth-

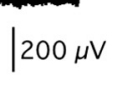

esis, we examined the effect of the lowaffinity, competitive glutamate receptor antagonist $\quad \gamma$-D-glutamylglycine $\quad(\gamma$ DGG). This drug, which blocks glutamate receptors when the glutamate concentration is low, should, at specific concentrations, selectively reduce an EPSC mediated by receptors that are distant from a glutamate release site while leaving unaffected direct synaptic signals (Wadiche and Jahr, 2001; Satake et al., 2006). Indeed, consistent with ET-to-MC excitation reflecting diffuse signaling, we found that $\gamma$-DGG $(500 \mu \mathrm{M})$ reduced the ET-to-MC EPSC (sub-LLD responses) evoked by direct ET cell stimulation (62 $\pm 9 \%$ reduction in charge; $n=4$; $p=0.006$; Fig. $8 b, c)$ but not the OSN-to-ET cell EPSC evoked by OSN stimulation (19 \pm $13 \%$ amplitude reduction by $500 \mu \mathrm{M}$ $\gamma$-DGG; $n=5 ; p=0.23)$. A differential sensitivity between ET-to-MC and OSN-to-ET cell excitation was specific to the low-affinity antagonist, not being observed for NBQX $(10 \mu \mathrm{M})$ plus DL-APV (100 $\mu \mathrm{M} ;>95 \%$ block for ET-to-MC excitation, $n=2$; $95 \pm 2 \%$ block of the OSN-to-ET cell EPSC, $n=4$ ). In addition to affecting the MC EPSC evoked by direct ET cell stimulation, $\gamma$-DGG also reduced the MC EPSC evoked by OSN stimulation $(71 \pm 5 \%$ reduction in charge integral for sub-LLD responses; $n=$ 4; Fig. $8 c, d$ ). Thus, diffuse signaling dominates under conditions in which signaling is initiated by OSNs as well as direct stimulation of ET cells.

\section{Discussion}

In our study, experiments were done in OB slices from rats and transgenic mice to examine the relative contribution of direct versus multistep mechanisms of excitatory signaling from OSNs to MCs.

\section{Negligible direct signaling from OSNs onto MCs}

In contrast to the prevailing view, we found that MCs do not receive substantial direct electrical signals from OSNs capable of driving spikes. This conclusion was based, first, on the kinetics of the MC response to OSN stimulation in whole-cell patch recordings from the MC soma. Most MCs did not have EPSCs with the rapid onset and rise time kinetics $(<4 \mathrm{~ms})$ predicted for direct signaling. In addition, the MC EPSC was sensitive to two pharmacological manipulations, including TTx, which should selectively inhibit polysynaptic mechanisms, as well as $\gamma$-DGG, which should act on diffuse rather than direct synaptic mechanisms. The failure to observe significant OSN-EPSCs in MCs was not an artifact of our $4 \mathrm{~ms}$ kinetic criteria, as we could record large, fast EPSCs within $2 \mathrm{~ms}$ after OSN stimulation in tufted cells and, more importantly, in MCs themselves with recordings done in Cx36 KO mice. The lack of significant OSN-EPSCs in MCs was also not due to poor stimulation of OSNs since (1) strong OSNEPSCs could be observed in ET cells during simultaneous recordings from same-glomerulus MCs and ET cells; (2) most MCs did 
a
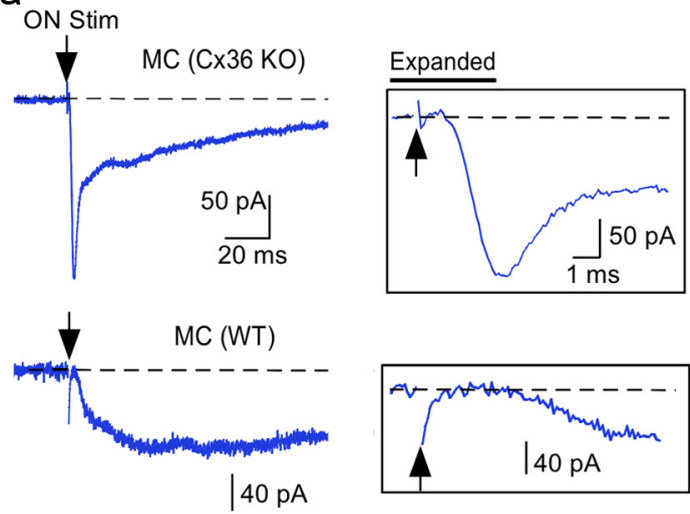

b

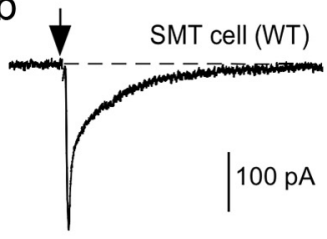

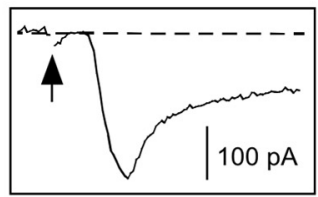
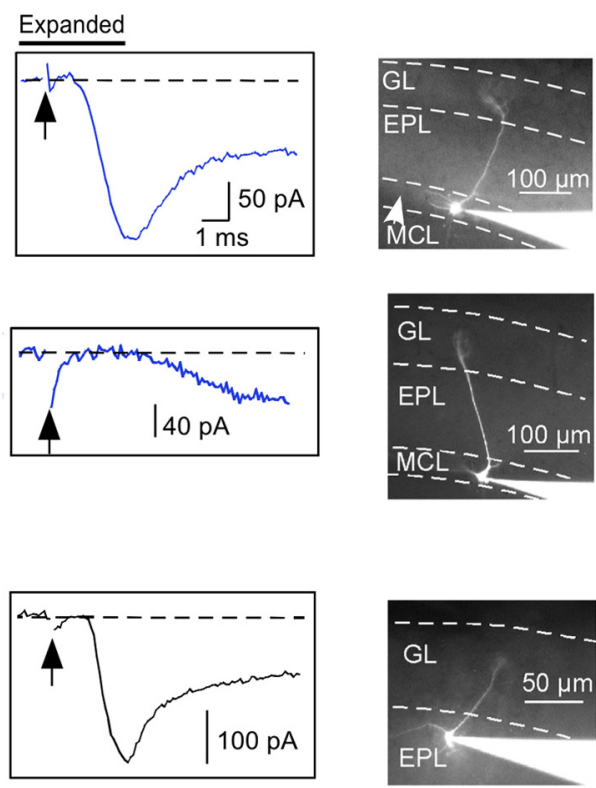

C
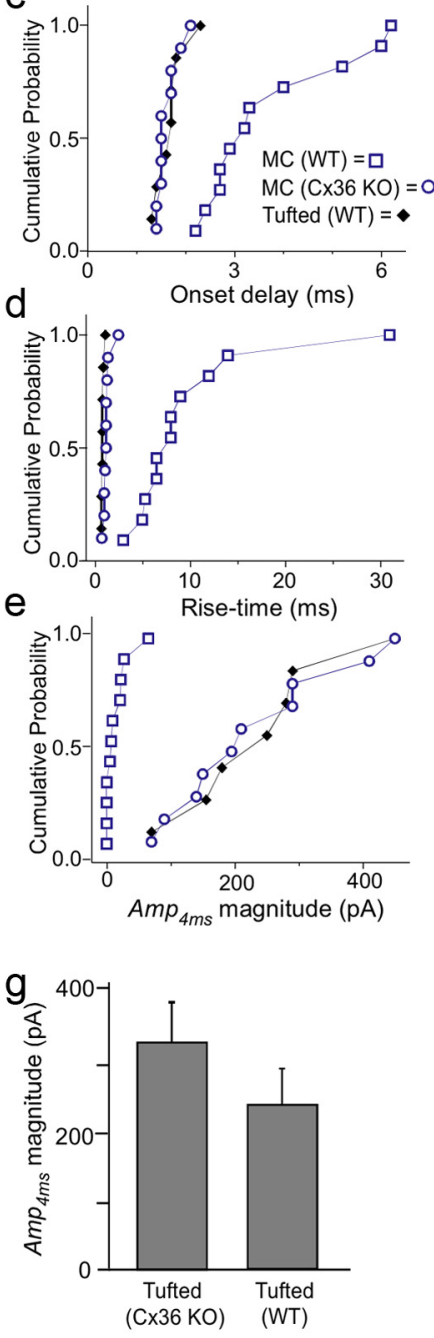

f

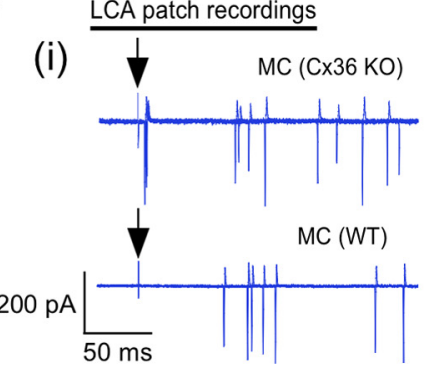

(ii)

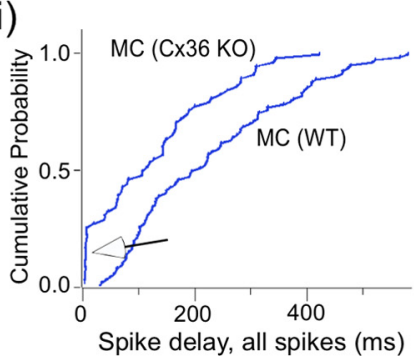

Figure 6. Cx36-mediated gap junctions shunt direct OSN signals on MCs. $\boldsymbol{a}$, Example recordings (averages of $10-15$ responses) from a MC in Cx36 K0 mice (top) and WT mice (bottom). Note that, in KO mice, MCs have a large, rapid current absent in WT mice. $\boldsymbol{b}$, Recording from an SMT cell from WT mice. c-e, Summary of EPSC measurements across 10 MCs in Cx36 K0 mice, 11 MCs in WT mice,

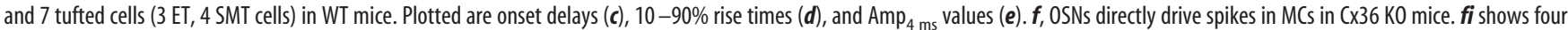
superimposed trials in MCs from KO mice (top) that included rapid-occurring spikes, absent in WT mice (bottom). The distribution of spike times in KO mice (fii) had a clear rapid component (open arrow). $\boldsymbol{g}$, (X36 KO did not significantly affect the amplitude of the OSN-EPSC in tufted cells, suggesting that OSN connectivity was not dramatically affected by K0. Error bars indicate SE.

not display significant fast signals in response to light stimulation of ChR-expressing OSNs, which activated OSNs broadly and specifically; and (3) all MCs in Cx36 KO mice had large, fast OSNEPSCs under identical OSN stimulation conditions.

Based on an analysis of MC response kinetics and TTx sensitivity, we found a subset of MCs, $20-30 \%$ of the total, with small-to-moderate putative direct OSN EPSCs. However, the functional significance of these signals is unclear, and, indeed, in cell-attached recordings from MCs, we found that direct OSN signals were never successful at driving spikes (Fig. 2). Also, however one interprets the putative direct OSN signal in MCs, it is important to point out that direct OSN signals were much larger in tufted cells, by a factor of 10-30 depending on the analysis method. The difference in size of the direct OSN signal in mitral versus tufted cells contributes to a multistep path being much more important in activation of MCs (see below).

Mechanistically, the very small direct OSN signal at the MC soma appears to reflect shunting by gap junctions on the $\mathrm{MC}$ apical dendrite rather than few anatomical OSN-to-MC connections. This conclusion was based on the fact that strong
OSN-EPSCs emerged in MCs in Cx36 KO mice. In our $\mathrm{KO}$ experiments, we were unable to exclude compensation effects (i.e., a scenario in which $\mathrm{KO}$ causes OSN-to-MC synapses to develop that are otherwise rare). However, a situation in which there are few OSN-to-MC synapses in normal animals would certainly be of no less interest than our proposed shunting mechanism, since it would go against the prevailing view about how OSNs signal to MCs. If our conclusion is true, that OSN-to-MC synapses exist but do not cause MCs to spike, what might they do? One possibility is that they mediate localized, subthreshold dendritic voltage signals that drive spike-independent transmitter release (Castro and Urban, 2009). Another is that direct OSN signaling onto MCs develops with age, if gap junction expression decreases. Perhaps, as may occur for gap junctions in other circuits such as the retina (Blankenship and Feller, 2010), gap junctions function in young animals to coordinate $\mathrm{MC}$ development. Electrical coupling between MCs does appear to undergo moderate reductions during the first several weeks of life (Maher et al., 2009), with coupling coefficients being reduced from $\sim 12 \%$ at P7-P10 to $\sim 3 \%$ at P31-P40. This would fit roughly with the fact that the 
a ET-to-MC excitatory current

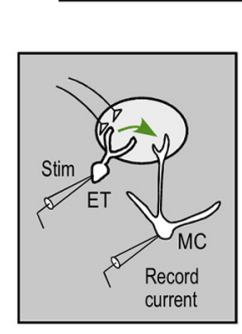

C

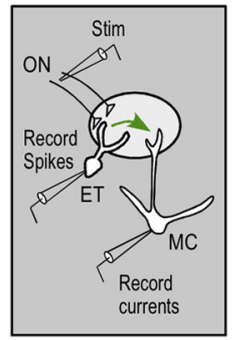

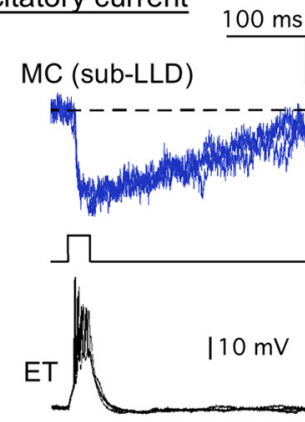

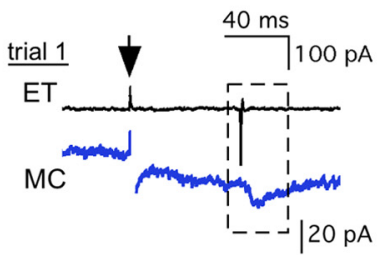

$\underline{\text { trial } 2}$

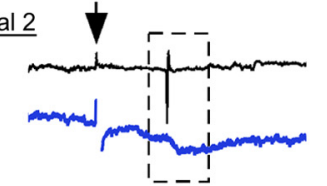

b

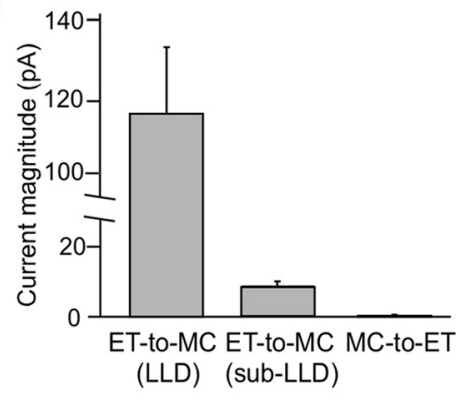

d

Spike-locked average

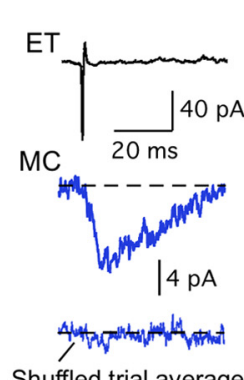

Shuffled trial average

Figure 7. ET cells mediate strong multistep excitation of MCs. $a$, Voltage-clamp recording of MC excitatory currents evoked by ET cell stimulation ( $400 \mathrm{pA}, 25 \mathrm{~ms}$ pulse) in an ET cell/MC pair. Four responses that were below threshold for generating an LLD are shown superimposed. This MCalso displayed large LLDs in othertrials (example in box). Traces ofET cell voltage are shown at bottom. $\boldsymbol{b}$, Summary of MCEPSCs evoked by ET cell stimulation, including both large LLD and small sub-LLD responses $(n=5)$. Histogram also includes the amplitude of the ET cell response to MC stimulation (MC-to-ET; $n=8)$, showing that ET-to-MCtransmission is unidirectional. $\boldsymbol{c}, \boldsymbol{d}$, Simultaneous recordings of responses to 0 Nstimulation $(16 \mu \mathrm{A})$ in a same-glomerulus ET cell/MC pair. In the two displayed trials in c, inward excitatory current events in the MC are locked to single spikes in the ET cell (recorded in LCA patch mode; see dashed boxes). The spike-locked EPSC is also evident in the averaged traces in $\boldsymbol{d}(n=35)$, which is shown along with a control trace taken from shuffled trials. The onset latency of the MC current was measured by extrapolating a line fitted to the current rising phase to baseline. Error bars indicate SE.

a

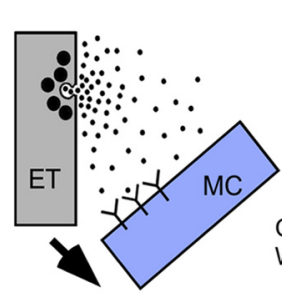

b

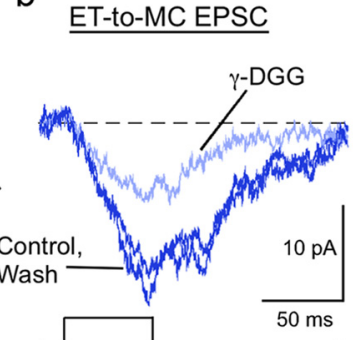

Stim ET cell

C

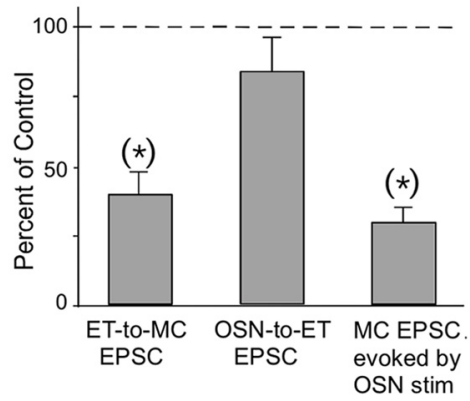

d

\section{EPSC evoked by OSN stim}

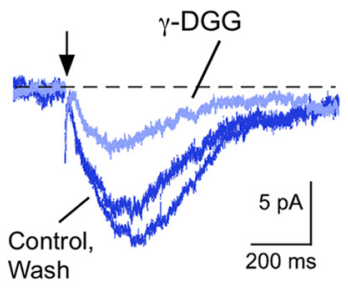

Figure 8. Diffuse ET-to-MC signaling. $\boldsymbol{a}$, Possible mechanism of ET-to-MC signaling in glomeruli: ET cells release glutamate from their dendrites, which acts on extrasynaptic glutamate receptors on MCs. $\boldsymbol{b}$, The low-affinity competitive glutamate receptor antagonist $\gamma$-DGG $(500 \mu \mathrm{M})$ reversibly reduced the EPSC in a MC (sub-LLD response) evoked by direct stimulation of an ET cell at the same glomerulus ( $500 \mathrm{pA}$, $50 \mathrm{~ms}$ pulse). $\gamma$-DGG $(500 \mu \mathrm{m})$, however, did not impact the EPSC in an ET cell evoked by stimulation of OSNs $(20 \mu \mathrm{A}, 100 \mu \mathrm{s}$; in box). All traces in figure are averages of five responses. c, Summary of $\gamma$-DGG effects on various EPSC, including the MCEPSC evoked by directET cell stimulation (left bar), theET cell EPSC evoked by OSN stimulation (middle bar), and the MCEPSC evoked by OSN stimulation (right bar). All MCEPSC analyzed were sub-LLD responses. $\boldsymbol{d}$, The EPSC in a MC evoked by OSN stimulation was strongly reduced by $\gamma$-DGG. Error bars indicateSE. ${ }^{*} p<0.05$.

apparent OSN-EPSC in MCs in our studies did increase modestly from $\sim 7 \mathrm{pA}$ at $\mathrm{P} 10-\mathrm{P} 14$ to $\sim 20 \mathrm{pA}$ at P24-P30.

What explains the difference between our study, which concludes that MCs generally receive very weak direct OSN signals, from prior studies that report substantial fast signals attributed to direct OSN-to-MC signaling (Chen et al., 1997; Carlson et al., 2000; Djurisic et al., 2008; De Saint Jan et al., 2009; Najac et al., 2011)? The age of the test animals, and possible differences in gap junctional coupling, does not appear to be a major factor. Most of the prior studies were done in rodents between P14 and P30, and even our somewhat older rats at P24-P30 had quite small OSN-EPSCs in MCs $(\sim 20$ pA). Also, our optogenetic experiments showing weak direct OSN-to-MC signaling were done in 4- to 5-week-old mice. Could differences in the method of stimulating OSNs explain the different conclusions about OSN-signaling? In our analysis, we found that electrical stimulation, the method used in prior studies to activate OSNs, can lead to large, fast EPSCs in MCs, but only at higher stimulation intensities that also directly activated MC apical dendrites. This result suggests that fast signals evoked by stimulation in the ON layer could 
reflect MC-to-MC lateral excitation rather than OSN-to-MC signals. The recent study by Najac et al. (2011), which took some care in analyzing fast EPSCs evoked by electrical stimulation, argued that their fast signals were OSN-EPSCs based on their reversal of polarity upon depolarization. However, the exact mechanisms of lateral excitation to allow interpretation of such results are presently unresolved (Pimentel and Margrie, 2008). Despite the lack of complete resolution of the issue of what drives fast signals due to electrical stimulation, it is important to emphasize that, in our studies, MCs typically exhibited very small direct OSN-EPSCs when optogenetic stimulation methods were used that selectively excited OSNs.

\section{Multistep signaling mediated by tufted cells}

In addition to providing evidence that MCs receive very weak direct OSN signals, our studies also indicated that MCs receive strong multistep signals through tufted cells. The tufted cellmediated signal, the polysynaptic LLD, was $\sim 15$ - to 20 -fold larger than the putative direct OSN-EPSC in MCs (based on the $\sim 120$ and $\sim 7 \mathrm{pA}$ average signal magnitudes in responses to electrical stimulation). Tufted cells, rather than MCs, appear to play the critical role in generating the LLD, since we found that direct stimulation of tufted cells, but not MCs, routinely elicited an LLD. Also, tufted cells, and not MCs, can be driven to spike by direct OSN inputs (Fig. 2); this should result in global excitation throughout a glomerulus ideally suited for generating an LLD.

Mechanistically, the relative ease at which tufted cells are excited by direct OSN inputs appears to reflect the fact that they engage in only weak gap junctional coupling at apical dendrites. Hence OSN signals are not shunted as in MCs. Why are the multistep excitatory signals on MC apical dendrites derived from tufted cells not shunted by gap junctions in the manner of direct OSN signals? One explanation is the exact location of the participating glutamate receptors. Gap junctions may have larger effects on OSN signals if OSN-to-MC synapses are on more distal portions of the $\mathrm{MC}$ apical dendrite compared with the glutamate receptors that underlie tufted-to-MC signaling (Kasowski et al., 1999) (but see Kosaka et al., 2001). It is also possible that all signals in the $\mathrm{MC}$ apical dendrite are shunted by gap junctions to varying degrees. Functionally, strong shunting of excitatory signals at the apical dendrite might contribute to an all-or-none response across a glomerulus-specific network of MCs. By this mechanism, it is only when a glomerulus undergoes concerted activation, resulting in a massive glutamate transient that can be detected by MCs, that shunting can be overcome.

The notion that multistep excitation exists as a form of signaling onto MCs is by no means a novel result (De Saint Jan et al., 2009; Najac et al., 2011), yet our study is unique in that it argues that the multistep path is the dominant path. The OSN-to-tuftedto-MC signaling path is also distinct from simple recurrent excitation. Recurrent excitation, for example in neocortex (Douglas et al., 1995), occurs among excitatory cells of the same type, whereas multistep signaling in OB involves intermediary cells, tufted cells, that are distinct from MCs in active membrane properties (Liu and Shipley, 2008), interactions with GABAergic cells, as well as the structures to which they send output signals (Ezeh et al., 1993; Nagayama et al., 2004). Thus, in rough terms, the OB circuit may be similar to the retina, where input signals must pass through bipolar cells before reaching ganglion cells.

\section{Functional implications}

For olfactory information processing, our evidence that MC activation occurs through a multistep path involving tufted cells suggests that there is a layer of processing in OB between OSNs and MCs. Tufted cell-only-mediated processing, which could be mediated by interactions with GABAergic periglomerular cells (Hayar et al., 2004b; Murphy et al., 2005; Gire and Schoppa, 2009), may occur, for example, under conditions of low-tomedium excitation of OSNs, when tufted cells are directly activated by OSNs but there is no LLD to excite MCs. Having excitatory signals pass through tufted cells could also be important for coordinating responses across a glomerulus-specific population of MCs. Our results also add additional weight to a longstanding idea that MCs and tufted cells could mediate two distinct olfactory processing streams for signaling to cortex (Ezeh et al., 1993; Nagayama et al., 2004). In addition to having axons that go to distinct locations in the cortex, MCs and tufted cells appear to have markedly different mechanisms of excitation by OSNs. Tufted cells, being activated by direct OSNs, may be better suited than MCs to code odor concentration, for example.

\section{References}

Aroniadou-Anderjaska V, Zhou FM, Priest CA, Ennis M, Shipley MT (2000) Tonic and synaptically evoked presynaptic inhibition of sensory input to the rat olfactory bulb via $\mathrm{GABA}_{\mathrm{B}}$ heteroreceptors. J Neurophysiol 84:1194-1203.

Blankenship AG, Feller MB (2010) Mechanisms underlying spontaneous patterned activity in developing neural circuits. Nat Rev Neurosci 11:18-29.

Carlson GC, Shipley MT, Keller A (2000) Long-lasting depolarizations in mitral cells of the rat olfactory bulb. J Neurosci 20:2011-2021.

Castro JB, Urban NN (2009) Subthreshold glutamate release from mitral cell dendrites. J Neurosci 29:7023-7030.

Chen WR, Midtgaard J, Shepherd GM (1997) Forward and backward propagation of dendritic impulses and their synaptic control in mitral cells. Science 278:463-467.

Christie JM, Bark C, Hormuzdi SG, Helbig I, Monyer H, Westbrook GL (2005) Connexin 36 mediates spike synchrony in olfactory bulb glomeruli. Neuron 46:761-772.

Chuhma N, Tanaka KF, Hen R, Rayport S (2011) Functional connectome of the striatal medium spiny neuron. J Neurosci 31:1183-1192.

Deans MR, Gibson JR, Sellitto C, Connors BW, Paul DL (2001) Synchronous activity of inhibitory networks in neocortex requires electrical synapses containing connexin 36. Neuron 31:477-485.

De Saint Jan D, Hirnet D, Westbrook GL, Charpak S (2009) External tufted cells drive the output of olfactory bulb glomeruli. J Neurosci 29:2043-2052.

Dhawale AK, Hagiwara A, Bhalla US, Murthy VN, Albeanu DF (2010) Nonredundant odor coding by sister mitral cells revealed by light addressable glomeruli in the mouse. Nat Neurosci 13:1404-1412.

Djurisic M, Popovic M, Carnevale N, Zecevic D (2008) Functional structure of the mitral cell dendritic tuft in the rat olfactory bulb. J Neurosci 28:4057-4068.

Douglas RJ, Koch C, Mahowald M, Martin KA, Suarez HH (1995) Recurrent excitation in neocortical circuits. Science 269:981-985.

Ennis M, Zhou FM, Ciombor KJ, Aroniadou-Anderjaska V, Hayar A, Borrelli E, Zimmer LA, Margolis F, Shipley MT (2001) Dopamine $\mathrm{D}_{2}$ receptormediated presynaptic inhibition of olfactory nerve terminals. J Neurophysiol 86:2986-2997.

Ezeh PI, Wellis DP, Scott JW (1993) Organization of inhibition in the rat olfactory bulb external plexiform layer. J Neurophysiol 70:263-274.

Gire DH, Schoppa NE (2009) Control of on/off glomerular signaling by a local GABAergic microcircuit in the olfactory bulb. J Neurosci 29:13454-13464.

Hayar A, Karnup S, Shipley MT, Ennis M (2004a) Olfactory bulb glomeruli: external tufted cells intrinsically burst at theta frequency and are entrained by patterned olfactory input. J Neurosci 24:1190-1199.

Hayar A, Karnup S, Ennis M, Shipley MT (2004b) External tufted cells: a major excitatory element that coordinates glomerular activity. J Neurosci 24:6676-6685.

Hines ML, Carnevale NT (1997) The NEURON simulation environment. Neural Comput 9:1179-1209. 
Isaacson JS, Strowbridge BW (1998) Olfactory reciprocal synapses: dendritic signaling in the CNS. Neuron 20:749-761.

Kasowski HJ, Kim H, Greer CA (1999) Compartmental organization of the olfactory bulb glomerulus. J Comp Neurol 407:261-274

Kosaka K, Aika Y, Toida K, Kosaka T (2001) Structure of intraglomerular dendritic tufts of mitral cells and their contacts with olfactory nerve terminals and calbindin-immunoreactive type 2 periglomerular neurons. J Comp Neurol 440:219-235.

Kosaka T, Kosaka K (2004) Neuronal gap junctions between intraglomerular mitral/tufted cell dendrites in the mouse main olfactory bulb. Neurosci Res 49:373-378.

Liu S, Shipley MT (2008) Multiple conductances cooperatively regulate spontaneous bursting in mouse olfactory bulb external tufted cells. J Neurosci 28:1625-1639.

Ma J, Lowe G (2007) Calcium permeable AMPA receptors and autoreceptors in external tufted cells of rat olfactory bulb. Neuroscience 144:1094-1108.

Maher BJ, McGinley MJ, Westbrook GL (2009) Experience-dependent maturation of the glomerular microcircuit. Proc Natl Acad Sci U S A 106:16865-16870.

McGann JP, Pírez N, Gainey MA, Muratore C, Elias AS, Wachowiak M (2005) Odorant representations are modulated by intra- but not interglomerular presynaptic inhibition of olfactory sensory neurons. Neuron 48:1039-1053.

Murphy GJ, Glickfeld LL, Balsen Z, Isaacson JS (2004) Sensory neuron signaling to the brain: properties of transmitter release from olfactory nerve terminals. J Neurosci 24:3023-3030.

Murphy GJ, Darcy DP, Isaacson JS (2005) Intraglomerular inhibition: signaling mechanisms of an olfactory microcircuit. Nat Neurosci 8:354-364.

Nagayama S, Takahashi YK, Yoshihara Y, Mori K (2004) Mitral and tufted cells differ in the decoding manner of odor maps in the rat olfactory bulb. J Neurophysiol 91:2532-2540.

Najac M, De Saint Jan D, Reguero L, Grandes P, Charpak S (2011) Monosynaptic and polysynaptic feedforward inputs to mitral cells from olfactory sensory neurons. J Neurosci 31:8722-8729.

Nickell WT, Behbehani MM, Shipley MT (1994) Evidence for $\mathrm{GABA}_{\mathrm{B}^{-}}$ mediated inhibition of transmission from the olfactory nerve to mitral cells in the rat olfactory bulb. Brain Res Bull 35:119-123.

Parker PR, Cruikshank SJ, Connors BW (2009) Stability of electrical coupling despite massive developmental changes of intrinsic neuronal physiology. J Neurosci 29:9761-9770.

Petreanu L, Mao T, Sternson SM, Svoboda K (2009) The subcellular organization of neocortical excitatory connections. Nature 457:1142-1145.

Pimentel DO, Margrie TW (2008) Glutamatergic transmission and plasticity between olfactory bulb mitral cells. J Physiol 586:2107-2119.

Satake S, Song SY, Cao Q, Satoh H, Rusakov DA, Yanagawa Y, Ling EA, Imoto K, Konishi S (2006) Characterization of AMPA receptors targeted by the climbing fiber transmitter mediating presynaptic inhibition of GABAergic transmission at cerebellar interneuron-Purkinje cell synapses. J Neurosci 26:2278-2289.

Schoppa NE, Westbrook GL (2001) Glomerulus-specific synchronization of mitral cells in the olfactory bulb. Neuron 31:639-651.

Schoppa NE, Westbrook GL (2002) AMPA autoreceptors drive correlated spiking in olfactory bulb glomeruli. Nat Neurosci 5:1194-1202.

Schoppa NE, Kinzie JM, Sahara Y, Segerson TP, Westbrook GL (1998) Dendrodendritic inhibition in the olfactory bulb is driven by NMDA receptors. J Neurosci 18:6790-6802.

Shepherd GM, Chen WR, Greer CA (2004) Olfactory bulb. In: The synaptic organization of the brain (Shepherd GM, ed), pp 165-216. New York: Oxford UP.

Stuart G, Spruston N (1998) Determinants of voltage attenuation in neocortical pyramidal neuron dendrites. J Neurosci 18:3501-3510.

Urban NN, Sakmann B (2002) Reciprocal intraglomerular excitation and intra- and interglomerular lateral inhibition between mouse olfactory bulb mitral cells. J Physiol 542:355-367.

Wadiche JI, Jahr CE (2001) Multivesicular release at climbing fiberPurkinje cell synapses. Neuron 32:301-313.

Yu CR, Power J, Barnea G, O’Donnell S, Brown HE, Osborne J, Axel R, Gogos JA (2004) Spontaneous neural activity is required for the establishment and maintenance of the olfactory sensory map. Neuron 42:553-566.

Zhou Z, Belluscio L (2008) Intrabulbar projecting external tufted cells mediate a timing-based mechanism that dynamically gates olfactory bulb output. J Neurosci 28:9920-9928. 